\title{
Strategic Exploration and Practice of Physical Education Reform in Colleges and Universities
}

\author{
Hongmei Wang \\ Central South University of Forestry and Technology \\ Changsha, China
}

\begin{abstract}
In view of the current situation that the unhealthy lifestyle of college students leads to the continuous deterioration of physical fitness, in response to the national call for national fitness and health for all, this paper makes an analysis of the current predicament of physical education in colleges and universities. Set up the goal of teaching reform and take some measures to achieve the corresponding teaching reform results. From the improvement of teachers' own quality, it is suggested to set up the stage-by-stage linking of learning curriculum content $(1+3)$, cultivate students' learning community ability, set up students' learning process evaluation and characteristic evaluation, and the form of assisting network preview, review and spot check of homework after class, and establish an integrated learning mechanism inside and outside class, so as to help college students participate in sports activities from passivity to initiative in depth and establish a correct way of learning life. It has also formed an atmosphere of daily punch-in supervision, group evaluation of sports culture week at term end, and group performance and competition, and enriched the campus sports culture and formed a social atmosphere of national fitness and health for all.
\end{abstract}

Keywords-current situation; deep education; teaching difficulties; reform results

\section{INTRODUCTION}

Nowadays, the society is a big data age with rapid development. With the rapid development of science and technology and the circulation of network information, living conditions are becoming more and more convenient. College students are one of the most skilled social groups in information technology. The convenience makes them dwell in dormitories for a long time, indulging in online games and social networking, and extremely lacking exercise. As a result, their physical fitness becomes worse and worse. For 25 years, the physical fitness of our students has been on decline, and obesity and myopia rate (myopia rate of college students reached to $83 \%$ ) has been increasing year by year.

In 2014, the Ministry of Education promulgated Basic Standards for Physical Education Work in Colleges and Universities. In 2016, the State Council issued Opinions on Strengthening Physical Education in Colleges and Universities and Promoting the All-round Development of Students' Physical and Mental Health and Program Outline of Health China by 2030. The sixth chapter of the outline "improving the physical quality of the whole people" wrote in the fourth section: the teenagers should be proficient in more than one sports skill, ensure that the students have no less than one hour of sports activities every day, and that the teenagers should participate in moderate-strength sports activities more than three times a week.

In the 19th National Congress of the Communist Party of China, General Secretary Xi called for speeding up the construction of sports power. The report put forward the slogan of national fitness, health for all and well-off society for all.

Under the background of the new era, the lifestyle of students is worrying. It is urgent for colleges and universities to make further reform in order to set the specific quantitative goal of "improving the physical quality of the whole people" and response the call of the president. The deep reform of physical education is urgent in colleges and universities.

\section{The CURRENT PREDICAMENT OF PHYSICAL EDUCATION IN COLLEGES AND UNIVERSITIES}

Yang Hui believes that physical education in colleges and universities face at least 6 predicaments. The function of physical education is weakened in colleges and universities, and the actual status of physical education curriculum is low. The current education system neglects physical education; the public opinion is indifferent to physical education; the theory of school physical education is lack of guidance to practice; and the scientific research of physical education is lack of support to physic education [1]. This shows that there are many difficulties in physical education in colleges and universities. This article mainly analyzes physical education from the teaching of teachers and students and content.

\section{A. Unidirectional Technical Teaching, Causing Students to Passively Participate in Sports Activities}

In the current physical education teaching, paying attention to simple and single physical education technology teaching has always been the teaching mode adopted by teachers. Less attention has been paid to the teaching significance, motion principles and values behind the technology. This teaching mode leads to the lack of in-depth teaching of sports technology: students may have learned the technology, but did not understand the principle and application behind the technology, which may not leave a deep impression of sports in the profound sports situation. Eventually, students passively attend physical education class and do not participate in sports activities actively. At the same 
time, besides learning sports technology, there is a lack of learning from each other among students and in-depth exchange of movement and technology between teacher and student. Students cannot enjoy the learning process from the study of sports technology, and do not grasp the actual effect brought by sports, thus unable to establish the consciousness of active exercise. Naturally, they have no active exercise behavior.

\section{B. Large-class Dissimilated Learning Environment, Leading to Different Students' Interests and Different Bases}

Each student's physical quality and health condition are different from each other, as well as their physical conditions. Due to large-class teaching of physical education, it is difficult for teachers to do one to one teaching. Most of the physical education educators do not give full play to the students' subjective initiative, nor do they teach students in accordance with their aptitude for different physiques. At the same time, in the teaching evaluation, the teacher evaluation is single and takes a one-size-fits-all form, so that students cannot get due recognition and affirmation in the final evaluation. Thus, they may lose the motivation to pursue better and also lose interest and enthusiasm in the process of learning.

\section{Being Unable to Master and Apply Technology Effectively, Leading to Students' Ineffective Learning}

The mastery of sports skills can be acquired with relatively concentrated time and continuous time according to the law of mastering sports [2]. At present, college students' sports practice is limited to two classes a week, and there is no connection between class and extracurricular. It is far from meeting quantity and quality accumulation of movement learning on time. Students not proficient in movement mastery will not be confident to show their result and consolidate it after school, thus losing the best opportunity to extend and expand. Students in physical exercise cannot really get the correct, systematic principle of sports activities and correct sports life mode, and cannot make a better sports plan for themselves. General knowledge in sports cannot be popularized [1].

\section{PRoblems to Be Solved IN Physical EdUCATION REFORM IN COLLEGES AND UNIVERSITIES}

The reform of physical education is a change from singleness to pluralism, from one-sided learning to all-round learning, narrow learning to broad learning, so that students can enjoy learning in physical education and realize the coordination and sustainable development of physical education. This is the most comprehensive method.

\section{A. To Create a Good Teaching Situation and Encourage Students to Learn Actively}

Through the teaching of sports technology, students can acquire professional skills and improve the standardization of sports technology, improve and enhance physical strength. In a single sport, a good match is formed, and the highest skill of a single sport is the goal. In this way, we can maximize our potential to improve learning and work efficiency. In the practice of sports events, we should carry forward the spirit of fair, open and just sports, make positive, healthy and unremitting efforts, and take it as a normative force to show sports style, sports mentality, sports expectations and so on. This will guide the formation of good moral character of students.

\section{B. To Establish a Homogeneous Interest Class to Help Students of Same Hobby Learn from Each Other}

In the prescribed period of time, with the permission of abundant teaching venues, prepare the project teachers, and let the students choose their favorite sports. In this way, at least students of same hobby can be guaranteed to learn from each other and communicate. Teachers can also make preparations for teaching plans according to students' general level and flexibly use them in the form of teaching organization. They can transfer theoretical knowledge to students through textbooks. In the process of teaching, they should lay stress on teaching ways and methods. They should try to present the principles of sports movement technology in a more ideal form, so that students can repeatedly use theory to master technology in learning, consolidate technology and use technology to improve practical ability and physical quality in repeated use of technology.

\section{To Help Students Apply the Knowledge and Skills They Have Learned to Daily Life and Form a Sports Lifestyle by Applying What They Have Learned and Integrating It into Their Daily Life}

The purpose of physical education is to enable people to get a healthy lifestyle. It includes three aspects: physical health, mental health and social adaptability. Physical health refers not only to the absence of disease, but also to the physical ability to meet life needs and have positive energy to fulfill life challenges. Mental health refers to having stable emotions to face all kinds of frustrations in life. Of course, occasional emotional fluctuations are normal, and psychological fluctuations in sports process can be analogous to emotional fluctuations in life. Social adaptability refers to the ability to have good social health and maintain harmonious interpersonal relationships in life, so that people will have a sense of self-confidence and security in life. In physical education teaching, through a certain form of activity, teachers can teach students sports skills and help them experience sports spirit, form sports moral character, improve physical quality, and apply technology to life. This is the best effect of physical education teaching.

\section{THE REFORM AND INNOVATION MEASURES OF} PHYSICAL EDUCATION IN COLLEGES AND UNIVERSITIES

The important elements of PE teaching are PE teachers, students, curriculum content, teaching methods and evaluation. Therefore, these main aspects can be centered to make reform and achieve the goal of reform [3].

\section{A. To Strengthen the Construction of Teaching Staff and Improve the Overall Level of Teachers}

The updating speed of teachers' theory and the depth of their concept formation determine the height of personnel training. PE teachers need to go out at any time, update their knowledge and skills, and change their concept [4]. In order 
to improve the overall teaching and scientific research level of teachers, the dean is personally responsible for formulating a teacher training mechanism: teachers are required to actively participate in professional learning and improve their own physical quality and teaching level; encourages young teachers to actively study for doctorates. At the same time, teachers should make full use of the teaching materials in the process of teaching. The teaching materials are the combination of sports experts' wisdom. Teachers should fully excavate the contents of the teaching materials which can promote students' values, and help them master professional theoretical knowledge and improve their aesthetic value of sports, so that students may love sports.

Enhance strength of teachers' study and experts' training. According to the needs of the events, teachers can be sent out in batches to participate in professional training, including international and national referee training, but also to participate in the training of professional competence.

At the same time, teachers should form a common growth body. Set up forms of "two one" and "one two", so that teachers can make a teaching reflection once a week, participate a teaching and research activity once a month and training twice a week. Similarly, a "three-tier" supervision mechanism can be established to implement the system of mutual listening among teachers, college supervisors and school supervisors, and promote teachers to form the correct teaching mode and regularize the teaching procedure.

\section{B. To Deepen the Research of Curriculum Content and Establish the Stage-by-stage Teaching Content}

1) To build a skill-linking curriculum system with "one basis and three specialties": Before the teaching reform, the curriculum was set in $2+2$ mode (basic courses in first and second semesters; optional courses in the third and forth semesters). After the teaching reform, we implement the $1+3$ mode. In $2+2$ mode, students can't change their choice after selecting courses. In $1+3$ mode, students can change appropriately in the next three semesters. In $1+3$ mode, it takes the principle of differentiating treatment and emphasizing the key point: set up rehabilitation classes for students with physical and mental disorders. In international classes, take the principle of paralleling classroom teaching and clubs. In other words, set both traditional items and increase items gearing to international standards, so that students can adapt to international culture as soon as possible. In $1+3$ mode, there are about 20 courses offered in the last three semesters. Each item is designed progressively according to bridging, which is beneficial for students of different levels to select courses.

2) To enrich the course content with auxiliary tools: Try to create a teaching situation through small instruments, so that students may immerse in happy sports activities and release their nature [5]. For example, guide students to use rope skipping, rope ladder, frisbee, small dumbbell, yoga mat, markers, shuttlecock and other equipment to create different games and sports methods. In the game design, practice and competition, they can experience happiness, and develop sports interest.

3) To play the role of network media: Network teaching has also become a new form of curriculum. Skillfully use network data to expand the three-dimensional practice space in physical education. Students are guided to construct a platform for self-learning through videos of WeChat, microblog, jitter, etc., to generate new knowledge and review previous knowledge. Guide students to understand and appreciate the function and cultural background of sports events through the Internet. Guide students to use the network for exercise punch-in and video recording.

\section{To Pay Attention to the Cultivation of Students' Ability}

1) To adhere to the principle of putting students first and fostering students' awareness of independent study: The main body of teaching is students. Starting from the actual needs of students, it is the key of reform to teach students the most practical knowledge and skills, and cultivate students' selflearning sports awareness. At the same time, integrate theory with practice and cultivate students' awareness of sports cognition. In the traditional concept of technology teaching, teachers pay attention to the teaching of skills and ignore the penetration of knowledge principles, resulting in the phenomenon that students master technology and do not understand sports. The enlightenment of "civilize their spirit and exercise its physique" to us should be to pay attention to the cultivation of sports consciousness, and then impart sports skills.

2) To guide students to participate in classroom teaching design and improve students' autonomous learning ability: The main driving force of college students is self-identity and sense of belonging. In the reform, our school randomly selected 10 classes, asking students to actively participate in the design of teaching content, form, progress and evaluation form. Let the student design learning content with questions (what to learn, how to learn, how to evaluate), which has trained the student's study ability. Only by actively integrating into the class, can students carry forward the spirit of masters, give full play to their subjective initiative, and make PE teaching more enthusiastic.

\section{To Establish a Scientific Evaluation System and Correct Students' Learning Motivation}

The evaluation system of physical education emphasizes the establishment of an evaluation system with multiple contents, evaluation methods and evaluation subjects[6]. It is suggested to perfect the examination evaluation system, strengthen the evaluation assessment, and enrich the evaluation forms, so that students may be enabled to straighten their minds, form correct performance consciousness and improve their learning motivation in the process of actively facing the evaluation.

1) To enrich the content of process evaluation and encourages students to take part in extracurricular sports activities: Past process evaluation (20 points) only includes 
attendance, and $20 \%$ of the score does not affect the overall score of students. It is a good way to promote students' active participation in extracurricular exercise to make full use of evaluation process.

Set up the final exam qualification system: if attendance is lower than $1 / 4$ of total classes, cancel the final exam qualification. The lacking times of homework assignments exceeds $1 / 4$ of total class hours, cancel the final exam qualification. In addition, deduct two points for undone homework every time (absence from class once).

Set up reward system: participate in events of sports association, and with full attendance, reward 3 points; participate in school sports activities, reward 5 points; participate in provincial sports activities, award 8 points. Add 1 to 5 points to sports commissary and team leader according to their performance. All rewords shall not exceed 10 points.

2) To enrich the form of final examination and build the atmosphere of examination culture week: Single sports examination has no great impact on students. The purpose of sports is to create physical and mental pleasure. According to the event groups, develop different forms of examination. Thus, students take the examination as a kind of performance, experience the examination week as sports festival and cultural week.

Set up the form of replacing examination by performance. For example, carry out staged performance in martial arts and gymnastics, according to difficulties of basic courses and optional courses. In the first term, basic performances will be performed, and in the fourth term, school-level classes of calisthenics show creative performances, and school-level classes of sanda show actual combat performance.

Set up the form of replacing examination by competition. For example, in the fourth semester, arrange in-class and outclass competition for ball games.

\section{THE ACHIEVEMENTS OF PHYSICAL EDUCATION REFORM IN COLLEGES AND UNIVERSITIES}

Through the reform of teaching, teachers have changed their educational concepts, and the teaching of physical education mode has been deepened. While learning sports movements, students have improved their sports consciousness and physical quality, and have developed comprehensive abilities.

1. Teachers have strengthened their ability of in-depth teaching. Teachers teach students, and pay attention to the spread of sports theory and principles.

2. After completing the classroom study, students run around the school once a week and 16 times every semester. 160 students in 4 classes were sampled to exercise. The result showed that $98 \%$ of the students persisted in punching in.

3. Students can preview the teaching content independently, and learn by themselves during break and form the habit of video recording after class.

4. Students have formed a learning community, use the common spare time to complete after-school technical assignments assigned by teachers, and establish a good team relationship in practice and learning.

5. Students' extra-curricular amateur activities are rich and varied. A number of sports associations have actively carried out sports activities in and out of school, such as "welcoming cup" table tennis match in school, "three-to-three" basketball match, basketball shooting match, and the Table Tennis Invitational Competition in Hunan Universities. It has cultivated students' hobbies and enriched their campus cultural life. In the school basketball league matches, the performance of the campus cheerleading team has promoted the establishment and development of campus culture. Campus football teaching competition system (five matches on a small stadium, seven to seven on a half football field, 11 to 11 on the full football field), as a kind of campus football culture, has promoted the reform of college physical education and made sports become the manifestation of normalization sports in life of college students.

\section{CONCLUSION}

In today's era, colleges and universities shall take measures in physical education to response to the call for national fitness and health for all. According to the specific physical quality of students, this paper makes a concrete analysis, and pays attention to continuity and periodicity in the teaching of sports skills. It is suggested to consider homogeneity in the student group, give students a chance of self-selection and self-evaluation, and establish a system of integrating class training and after-class training together, so that students can practice technology they learned in class repeatedly after class and exercise in daily life. It helps students improve their physical quality and skills in life, and form a healthy lifestyle.

\section{REFERENCES}

[1] Yang Hui. Problems and Solutions of Physical Education in Colleges and Universities. Sports Journal, 2014, 21 (04): 71-76.

[2] Mao Zhenming \& Yang Duoduo. Program Outline of Healthy China by 2030 and Measures for School Physical Education Reform (1) - Goal: Young People Master More than One Sports Skills. Journal of Wuhan Institute of Physical Education, 2018, 52 (02): 5-10.

[3] Gui Ming, Qi Guoqiang and Li Fengxiang. A Preliminary Study on the Reasonable Allocation of Resources in College Physical Education Reform - Practical Research on the Reform of Physical Education in Shandong University of Science and Technology. Journal of Beijing Sports University, April 22-24, 2003

[4] Zhu Huifang \& Cai Min. College Physical Education Reform in the Perspective of General Education. Journal of Beijing Sports University, 2011, 10. 92-95.

[5] Wang Yukuo, Chen Qinghe \& Li Huizeng. Research on the Reform and Development of Physical Education in Higher Vocational Colleges. Journal of Beijing Sports University, 2005, 7. 960-961.

[6] Wei Shenghui, Yan Haibo. Dissimilation and Planning of Physical Education Teaching Evaluation System in Colleges and Universities in China. Journal of Guangzhou Institute of Physical Education, 2014, 34 (05): 10-13. 